\title{
How full is your glass? Portion sizes of wine, fortified wine and straight spirits at home in the Netherlands
}

\author{
Myrthe FA de Beukelaar ${ }^{1}$, Marion L Janse ${ }^{2}$, Aafje Sierksma ${ }^{2}$, Edith JM Feskens ${ }^{1}$ and \\ Jeanne HM de Vries ${ }^{1, *}$ \\ 'Division of Human Nutrition and Health, Wageningen University and Research, PO Box 17, 6700 AA \\ Wageningen, The Netherlands: ${ }^{2}$ The Dutch Beer Institute, Wageningen, The Netherlands
}

Submitted 7 May 2018: Final revision received 23 November 2018: Accepted 8 January 2019: First published online 26 March 2019

\begin{abstract}
Objective: Alcohol consumption may be wrongly estimated because of inaccurate information on actual portion sizes. We compared portion sizes of wine, fortified wine and straight spirits poured at home with the Dutch standard drink sizes.

Design: Participants measured portion sizes of wine, fortified wine and straight spirits at home up to a maximum of three times and reported these via an online survey. Average portion sizes (in millilitres) were compared with the Dutch standard drink sizes. Portion sizes were compared between subgroups of gender, age, BMI and level of education, and for different glass types.

Setting: Wageningen and surroundings, the Netherlands.

Participants: Adults ( $N 201$ ) living in the Netherlands and consuming wine and/or straight spirits at home at least once per week.

Results: Participants poured on average $129.4 \mathrm{ml}$ white wine and $131.7 \mathrm{ml}$ red wine, which is significantly more than the standard of $100 \mathrm{ml}$. For fortified wine, the average poured amount was $94.0 \mathrm{ml}$, significantly more than the standard of $50 \mathrm{ml}$; also for straight spirits the poured amount was significantly more than the standard ( 47.0 v. $35 \mathrm{ml})$.

Conclusions: Participants' portion sizes of wine, fortified wine and straight spirits poured at home were on average larger than the Dutch standard drink sizes. This suggests that at-home alcohol consumption in the Netherlands is underestimated.
\end{abstract}

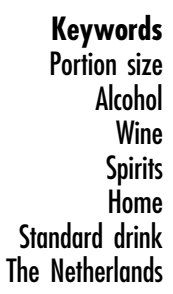

The alcohol guideline of the Dutch Health Council states: 'do not drink alcohol, or at least no more than one glass per day $^{,(1)}$. In 2015 , it was estimated that on average $45 \%$ of the total Dutch population aged 19-79 years adhered to this guideline; approximately $36 \%$ of the men and $53 \%$ of the women drank no more than one glass of alcohol per day on average ${ }^{(2)}$.

Accurate estimates of energy and nutrient intakes of individuals and populations rely on information obtained about dietary intake, food composition and portion size ${ }^{(3)}$. Portion sizes of alcoholic beverages are often estimated in terms of standard drinks. In the Netherlands, one standard drink of alcohol corresponds to $10 \mathrm{~g}$ ( $12 \mathrm{ml}$ ) alcohol, which is approximately the amount of alcohol in $250 \mathrm{ml}$ beer ( $5 \%$ alcohol), $100 \mathrm{ml}$ wine ( $12 \%$ alcohol), $50 \mathrm{ml}$ fortified wine (15\% alcohol) and $35 \mathrm{ml}$ straight spirits $(35 \%$ alcohol $)^{(1)}$. Noteworthy is that The Netherlands Nutrition Centre recently published different drink sizes based on consumer practices: $150 \mathrm{ml}$ for wine, $75 \mathrm{ml}$ for fortified wine and $50 \mathrm{ml}$ for straight spirits ${ }^{(4)}$. The standard drink sizes are used for dietary monitoring and to make recommendations about alcohol consumption in relation to health. Furthermore, most surveys assessing alcohol levels, such as the Dutch National Food Consumption Survey, rely on the assumption that respondents use these standard drink sizes. However, knowledge of the term 'standard drink' by respondents is shown to be poor in self-reports of alcohol consumption ${ }^{(5-7)}$. As a result, the amount of self-reported drinks (given in standard servings) might not match the actual amount of alcohol consumed, leading to misreporting of alcohol consumption in the Netherlands.

To date, most of the research on the practice of pouring alcoholic beverages has focused on drink size variation in relation to pouring on-premises. Across these studies, drinks typically contained greater volumes of alcohol than one standard drink ${ }^{(8-11)}$, even when alcoholic beverages were poured by professional bartenders ${ }^{(10)}$. This effect was demonstrated in wine and in (mixed) straight spirits, whereas volumes of alcohol in beer and shots (unmixed 
spirits) were relatively similar to standard drink volumes. Fewer studies have investigated drink size variation in relation to self-serving off-premises. In a study in which the mean alcohol content of beer, wine and spirits was estimated in a national sample of US drinkers, a weighted mean alcohol content of $15.6 \mathrm{~g}$ overall, $13.1 \mathrm{~g}$ for beer, $15.4 \mathrm{~g}$ for wine and $20.8 \mathrm{~g}$ for spirits was revealed ${ }^{(12)}$, suggesting that the US alcohol drink standard ( $14 \mathrm{~g}$ alcohol per drink) underestimates the average alcohol content in glasses of wine and spirits poured at home. In Europe, a study in a Scottish population showed a considerable variation in the amount of wine or spirits that was poured. On average, the amount poured equalled approximately two UK standard units instead of one $(8 \mathrm{~g} \text { per drink })^{(13)}$. In 65- to 74-year-olds from Western Australia, larger volumes of wine and spirits were poured in comparison to a standard drink (10 g); $32 \%$ more for men and 16\% more for women $^{(14)}$. A study conducted in 1994 among Dutch participants found that drink sizes varied off-premises and that they were on average larger than a standard drink ${ }^{(15)}$. The deviation from the presumed standard ( $10 \mathrm{~g}$ per drink) was highest for spirits (+26\%), followed by fortified wine $(+14 \%)$ and least for wine $(+4 \%)^{(15)}$. Thus, errors in drink size likely contribute to the under-reporting of alcohol consumption. This is specifically relevant for beverages that do not come in drink-size containers ${ }^{(16)}$, since not all individuals use the same type of glassware to pour alcoholic beverages at home. In fact, elongation of glasses has been shown to influence how much alcohol people pour: tall, slender glasses lessen the tendency and short, wide glasses increase the tendency to overpour ${ }^{(10,17)}$.

The last study in the Netherlands focusing on portion sizes of alcoholic beverages off-premises was more than 20 years ago ${ }^{(15)}$. The aim of the present study was to provide an update of the portion sizes of wine and straight spirits poured at home and compare them with the Dutch standard drink sizes and the drink sizes based on consumer practices. In addition, the study evaluated whether gender, age, BMI and level of education, and different glass types have an association with poured portion sizes. Beer and pre-mixed drinks were excluded because, at home, consumers mostly use standard units such as bottles and cans of which the contents are known.

\section{Methods}

\section{Study design and participants}

The present study was a cross-sectional observational study, designed to obtain information on the portion sizes of wine, fortified wine and straight spirits poured at home in a sample of adults living in the Netherlands. Between July and September 2017, adult men and women were recruited: (i) from the 'EetMeetWeet' research panel ${ }^{(18)}$; (ii) via a call on social media (Facebook, LinkedIn); and (iii) via direct approach from the researchers at a local supermarket and at a local public event, both in Wageningen. Inclusion criteria were a minimum age of 18 years old, living in the Netherlands, wine and/or straight spirits consumption at home at least once per week, and willing to measure wine and/or straight spirits poured at home on several days. No ethical approval was required for the present study. The Medical Ethics Committee of Wageningen University concluded that this research does not fall within the remit of the 'Medical Research Involving Human Subjects Act', because participants are not subject to procedures or required to follow rules of behaviour. In addition, it does not concern medical scientific research. All participants declared to have read and understood the goal of the study.

\section{Procedure}

Participants of the study were asked to measure the portion size (in millilitres) of wine, fortified wine and straight spirits in glasses they normally use at home. They received instructions by email, supported by a short video on how to measure the content of a glass. After pouring their drink into their usual glass, participants used a measuring cup for the measurements, which was provided by the researchers. The total duration of the study was different for each participant, as they could choose when to measure their alcoholic beverages within a period of two months (August and September 2017). Participants were requested not to change their habits of alcoholic beverage pouring and drinking.

Participants filled out an online survey created in LimeSurvey ${ }^{(19)}$ asking for the following information: the date of measurement, type of beverage, portion size in millilitres, alcohol content of the beverage indicated on the bottle (volume percentage) and the type of glass (relevant number or letter) in which they had poured their drink (see Fig. 1). Participants placed wine in one of the following categories: white wine, red wine, rosé, sparkling wine, dessert wine, port, sherry and other. The type of straight spirits was identified with an open question. Measurements of the same types of beverages were repeated up to a maximum of three times, each measurement made on a different day. In addition, gender, age, height and weight (in order to calculate BMI) and highest level of education completed (elementary, secondary, higher professional or scientific education) were asked to compare portion sizes between specific subgroups.

\section{Data analysis}

All data were analysed in the statistical software package IBM SPSS Statistics for Apple Mac version 24. The average portion sizes (in millilitres) of white wine, red wine, rosé, other wine (sparkling wine and dessert wine), fortified wine (port and sherry) and straight spirits poured at home were calculated per participant. The fortified wine category included the average portion sizes of both port and 


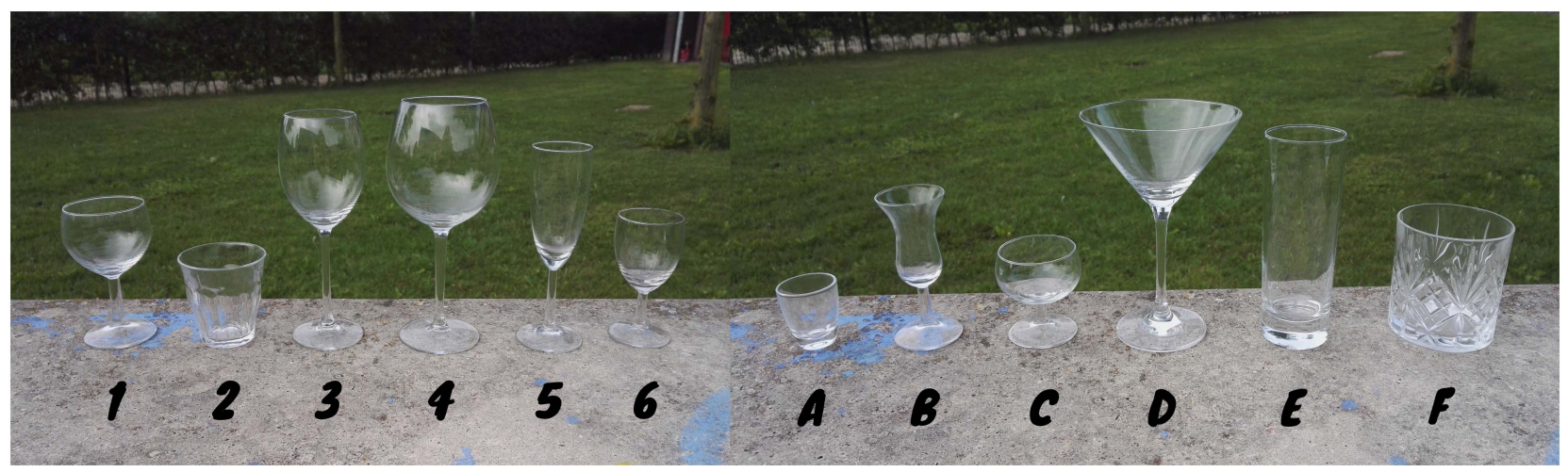

Fig. 1 (colour online) Glass types 1 to 6 for wine and fortified wine (left) and glass types A to F for straight spirits (right), as presented in the survey. Participants could indicate that they had used another glass type than those presented

sherry, based on similarities between standard drink size and alcohol content. Straight spirits were analysed in total and by alcohol volume percentage $(<30 \%, 30-40 \%$ or $>40 \%$ ). By inspection of boxplots, outliers were perceived in the data of white wine, red wine and rosé. Data were analysed with and without outliers. Analyses without outliers resulted in slightly lower means for the average portion sizes of white wine, red wine and rosé, but did not affect statistical significance. Thirty-one and twenty-four participants performed only one measurement for white wine and red wine, respectively, but means and standard deviations for the portion sizes of wine and straight spirits were similar. Therefore, data of all 201 participants were included for analysis.

The average portion sizes per participant were normally distributed for white wine, red wine, rosé, other wine, fortified wine and for straight spirits, as assessed by inspection of $\mathrm{Q}-\mathrm{Q}$ plots and histograms. One-sample $t$ tests were run to determine whether the mean portion sizes of each single type of wine (white wine, red wine, rosé, other wine), of fortified wine and of straight spirits deviated significantly from the standard drink sizes: $100 \mathrm{ml}$ for wine, $50 \mathrm{ml}$ for fortified wine and $35 \mathrm{ml}$ for straight spirits. One-sample $t$ tests were also run to assess whether the mean portion sizes of the wines, fortified wine and straight spirits deviated significantly from the consumerbased drink sizes published by The Netherlands Nutrition Centre: $150 \mathrm{ml}$ for wine, $75 \mathrm{ml}$ for fortified wine and $50 \mathrm{ml}$ for straight spirits ${ }^{(4)}$. All $P$ values were two-sided; $P<0.05$ indicated statistical significance.

ANOVA tests were used to determine whether the distribution of mean portion sizes of the wines, fortified wine and straight spirits differed significantly across categories of gender (men $v$. women), age ( $\leq 50 v .>50$ years), BMI $\left(\leq 25.0 \quad v . \geq 25.1 \mathrm{~kg} / \mathrm{m}^{2}\right.$ ) and education (elementary or secondary education $v$. higher professional or scientific education).

To assess whether glass type (shape and size) was associated with portion size, a one-way ANOVA was used for all types of wine separately and for straight spirits. When significant main associations were found using
ANOVA, post hoc comparisons were done using least significant difference tests. In all tests, $P<0.05$ indicated statistical significance.

\section{Results}

\section{Participant characteristics}

Table 1 shows the characteristics of the 201 participants, including seventy-eight members of the 'EetMeetWeet' research panel and 123 participants who were recruited via social media or via direct approach from the researchers. The majority were female $(60.7 \%)$, their mean age was 55 (SD 16) years and they were not overweight on average (mean $\left.\mathrm{BMI}=24 \cdot 0(\mathrm{sD} 3 \cdot 1) \mathrm{kg} / \mathrm{m}^{2}\right)$. The sample was relatively highly educated, with $69.7 \%$ of the participants reporting to have completed higher professional or scientific education. The 'EetMeetWeet' participants did not differ from the other participants except for their age, which was higher (mean age $=62(\mathrm{SD} 11)$ years $v .51$

Table 1 Characteristics of the 201 participants from Wageningen and surroundings, the Netherlands, July-September 2017

\begin{tabular}{|c|c|c|}
\hline & $\begin{array}{l}\% \text { or } \\
\text { Mean }\end{array}$ & $N^{*}$ or SD \\
\hline Gender female, $\%$ and $N$ & $60 \cdot 7$ & 122 \\
\hline \multicolumn{3}{|l|}{ Age (years), $\%$ and $N$} \\
\hline $18-30$ & $12 \cdot 0$ & 24 \\
\hline $31-50$ & $20 \cdot 0$ & 40 \\
\hline $51-70$ & 53.0 & 107 \\
\hline$>71$ & $15 \cdot 0$ & 30 \\
\hline Total (range $=18-83$ years), mean and SD & 55 & 16 \\
\hline \multicolumn{3}{|l|}{ BMI $\left(\mathrm{kg} / \mathrm{m}^{2}\right) \dagger$} \\
\hline$<18.5$ (underweight) & $2 \cdot 0$ & 4 \\
\hline $18.5-25.0$ (normal) & 65.5 & 131 \\
\hline $25 \cdot 1-30 \cdot 0$ (overweight) & 29.0 & 58 \\
\hline$>30.0$ (obese) & 3.5 & 7 \\
\hline $\begin{array}{l}\text { Total }\left(\text { range }=17 \cdot 2-34.5 \mathrm{~kg} / \mathrm{m}^{2}\right) \text {, mean and } \\
\text { SD }\end{array}$ & 24.0 & $3 \cdot 1$ \\
\hline \multicolumn{3}{|l|}{ Highest level of education completed, $\%$ and $N$} \\
\hline Elementary or secondary education & $30 \cdot 3$ & 61 \\
\hline Higher professional or scientific education & 69.7 & 140 \\
\hline
\end{tabular}

${ }^{*} N$, number of participants.

†One missing value for BMI, $N 200$. 
(SD 17) years, respectively). Therefore, results of both samples were combined.

\section{Portion sizes of wine and fortified wine}

Reported alcohol contents varied across participants and types of wine, with means of 12.2 (SD 1.4) \% vol. for white wine, $13 \cdot 1$ (SD 0.7) \% vol. for red wine, 12.3 (SD 1.4) \% vol. for rosé, $10 \cdot 7$ (sD 3.0) \% vol. for other wine and $17 \cdot 8$ (SD $2 \cdot 7) \%$ vol. for fortified wine.

Table 2 shows that the mean portion sizes of white wine, red wine, rosé and other wine were significantly higher than the standard drink size of $100 \mathrm{ml}$. In addition, the mean portion sizes of white wine and red wine were significantly lower than the drink size of $150 \mathrm{ml}$ of The Netherlands Nutrition Centre. The mean portion size of fortified wine (port and sherry) was significantly larger than both the standard drink size of $50 \mathrm{ml}$ and the drink size of $75 \mathrm{ml}$.

The mean portion sizes of white wine, red wine, rosé, other wine and port/sherry did not differ significantly across gender or BMI categories (data not shown). Only the mean portion size of rosé was significantly different across categories of education $(P=0 \cdot 007)$, with higher educated participants pouring on average smaller amounts of rosé (mean $=124.6(\mathrm{sD} 23 \cdot 4) \mathrm{ml}, n$ 20) than lower educated participants $($ mean $=169.8(\mathrm{sD} 61.7) \mathrm{ml}$, $n 10$; where $n$ is number of measurements). In addition, only the mean portion size of other wine was significantly different across categories of age $(P=0.03)$, with participants $\leq 50$ years old pouring on average larger amounts of other wine $($ mean $=176 \cdot 1(\mathrm{sD} 34 \cdot 7) \mathrm{ml}, n$ $5)$ than participants $>50$ years old $($ mean $=121 \cdot 5$ (SD 46.2) $\mathrm{ml}, n$ 13).

\section{Portion sizes of straight spirits}

The reported alcohol content in straight spirits ranged from $13 \%$ vol. to $46 \%$ vol., with a mean alcohol content of 35.7 (sD 6.6) \% vol. Table 3 shows that the mean portion size of all straight spirits taken together was significantly higher than the standard drink size of $35 \mathrm{ml}$, but not significantly lower than the drink size of $50 \mathrm{ml}$ of The Netherlands Nutrition Centre. The mean portion sizes of straight spirits with an alcohol content $<30 \%$ vol., between 30 and $40 \%$ vol. and $>40 \%$ vol. were all significantly higher than the standard drink size of $35 \mathrm{ml}$, although the higher the alcohol volume percentage, the smaller the mean portion size. Only the mean portion size of strong spirits (>40\% vol.) was significantly lower than the drink size of $50 \mathrm{ml}$.

The mean portion size of all straight spirits taken together was not significantly different across gender, age, BMI or education categories (data not shown). The mean portion size of strong spirits ( $>40 \%$ vol.) was significantly different across categories of age $(P=0.038)$, with participants $\leq 50$ years old pouring on average smaller amounts of strong spirits (mean $=34.6$ (sD 16.6) $\mathrm{ml}, n$ 13) than participants $>50$ years old $($ mean $=45.3(\mathrm{sD} 14 \cdot 9) \mathrm{ml}, n 33)$.

\section{Association of glass type with portion size}

Table 4 shows that there was a significant mean difference in portion size between the different glass types used for white wine $(P=0.001)$, for red wine $(P \leq 0.0001)$ and for other wine $(P=0.019)$. Significant differences in portion size were observed between glass type 4 and glass types 2 $(P \leq 0 \cdot 0001), 3(P=0.001)$ and $6(P=0.009)$ when comparing glasses used for white wine. Table 4 reveals a higher mean portion size of white wine in glass type 4 ,

Table 2 Measured portion sizes (in millilitres) of white wine, red wine, rosé, other wine and fortified wine, and differences as compared with reference drink sizes, in 201 participants from Wageningen and surroundings, the Netherlands, August-September 2017

\begin{tabular}{|c|c|c|c|c|c|c|c|c|}
\hline \multirow[b]{3}{*}{ Type of wine } & \multirow[b]{3}{*}{$N^{*}$} & \multirow[b]{3}{*}{$n \dagger$} & \multirow[b]{3}{*}{ Mean } & \multirow[b]{3}{*}{ SD } & \multicolumn{4}{|c|}{$P$ value $\ddagger$} \\
\hline & & & & & \multicolumn{4}{|c|}{ Reference drink sizes§ } \\
\hline & & & & & $100 \mathrm{ml}$ & $150 \mathrm{ml}$ & $50 \mathrm{ml}$ & $75 \mathrm{ml}$ \\
\hline White wine & 108 & 258 & 129.4 & $48 \cdot 3$ & $\leq 0.0001$ & $\leq 0.0001$ & $\mathrm{~N} / \mathrm{A}$ & $\mathrm{N} / \mathrm{A}$ \\
\hline Red wine & 141 & 392 & $131 \cdot 7$ & $44 \cdot 3$ & $\leq 0.0001$ & $\leq 0.0001$ & $\mathrm{~N} / \mathrm{A}$ & $\mathrm{N} / \mathrm{A}$ \\
\hline Rosé & 30 & 60 & $139 \cdot 7$ & $44 \cdot 8$ & $\leq 0.0001$ & 0.216 & $\mathrm{~N} / \mathrm{A}$ & $\mathrm{N} / \mathrm{A}$ \\
\hline Other wine & 18 & 33 & $136 \cdot 7$ & $49 \cdot 3$ & 0.006 & 0.268 & $\mathrm{~N} / \mathrm{A}$ & N/A \\
\hline Fortified wine & 36 & 63 & 94.0 & 41.4 & $\mathrm{~N} / \mathrm{A}$ & N/A & $\leq 0.0001$ & 0.009 \\
\hline
\end{tabular}

N/A, not applicable.

${ }^{\star} N$, number of participants.

$\dagger n$, number of measurements. When a single participant performed more than one measurement for the portion size of a certain type of wine, the average of all measurements was used.

$\ddagger P<0.05$ indicates a statistically significant difference between the mean and the reference drink size.

§Means were compared with the standard drink sizes of $100 \mathrm{ml}$ (wine) and $50 \mathrm{ml}$ (fortified wine), and with the consumer-based drink sizes published by The Netherlands Nutrition Centre of $150 \mathrm{ml}$ (wine) and $75 \mathrm{ml}$ (fortified wine). 
Table 3 Measured portion sizes (in millilitres) of total amount of straight spirits and of straight spirits grouped by alcohol volume percentage, and differences as compared with reference drink sizes, in 201 participants from Wageningen and surroundings, the Netherlands, AugustSeptember 2017

\begin{tabular}{|c|c|c|c|c|c|c|}
\hline \multirow[b]{3}{*}{ Alcohol volume percentage } & \multirow[b]{3}{*}{$N^{*}$} & \multirow[b]{3}{*}{$n \dagger$} & \multirow[b]{3}{*}{ Mean } & \multirow[b]{3}{*}{ SD } & \multicolumn{2}{|c|}{$P$ value $\ddagger$} \\
\hline & & & & & \multicolumn{2}{|c|}{ Reference drink sizes§ } \\
\hline & & & & & $35 \mathrm{ml}$ & $50 \mathrm{ml}$ \\
\hline Total (range: $13-46 \%$ vol.) & 87 & 195 & $47 \cdot 0$ & $17 \cdot 9$ & $\leq 0.0001$ & $0 \cdot 122$ \\
\hline$<30 \%$ vol. & 17 & 29 & $55 \cdot 9$ & 23.5 & 0.002 & 0.314 \\
\hline $30-40 \%$ vol. & 42 & 74 & $46 \cdot 6$ & $16 \cdot 1$ & $\leq 0.0001$ & 0.173 \\
\hline$>40 \%$ vol. & 46 & 90 & $42 \cdot 3$ & $16 \cdot 0$ & 0.003 & 0.002 \\
\hline
\end{tabular}

${ }^{*} N$, number of participants.

$\dagger n$, number of measurements. When a single participant performed more than one measurement for the portion size of straight spirits, the average of all measurements was used.

$\ddagger P<0.05$ indicates a statistically significant difference between the mean and the reference drink size.

$\S$ Means were compared with the standard drink size of $35 \mathrm{ml}$ and with the consumerbased drink size published by The Netherlands Nutrition Centre of $50 \mathrm{ml}$.

Table 4 Portion sizes (in millilitres) of white wine, red wine, rosé, other wine and fortified wine compared by type of glass in 201 participants from Wageningen and surroundings, the Netherlands, August-September 2017

\begin{tabular}{|c|c|c|c|c|c|c|c|c|c|c|c|c|c|c|c|c|c|c|c|c|}
\hline \multirow[b]{2}{*}{ Type of glass* } & \multicolumn{4}{|c|}{ White wine } & \multicolumn{4}{|c|}{ Red wine } & \multicolumn{4}{|c|}{ Rosé } & \multicolumn{4}{|c|}{ Other wine } & \multicolumn{4}{|c|}{ Fortified wine } \\
\hline & $N \dagger$ & $n \ddagger$ & Mean§ & SD & $N \dagger$ & $n \ddagger$ & Mean§ & SD & $N+$ & $n \ddagger$ & Mean & SD & $N+$ & $n \ddagger$ & Mean§ & SD & $N+$ & $n \ddagger$ & Mean & SD \\
\hline Type 1 & 5 & 8 & $123 \cdot 0$ & $15 \cdot 8$ & 10 & 24 & $127 \cdot 8^{\mathrm{C}}$ & $42 \cdot 4$ & 1 & 3 & $120 \cdot 0$ & - & 0 & 0 & \multicolumn{2}{|c|}{ N/A } & 1 & 1 & $90 \cdot 0$ & - \\
\hline Type 2 & 31 & 67 & $108 \cdot 3^{\mathrm{a}}$ & $26 \cdot 8$ & 43 & 89 & $111 \cdot 3^{\mathrm{a}, \mathrm{b}, \mathrm{c}}$ & 29.5 & 9 & 25 & 128.5 & 35.7 & 2 & 4 & $114 \cdot 2^{\mathrm{a}}$ & 36.5 & 7 & 11 & $75 \cdot 1$ & 25.6 \\
\hline Type 3 & 62 & 132 & $126 \cdot 2^{\mathrm{a}}$ & 38.8 & 65 & 147 & $134 \cdot 3^{\mathrm{c}}$ & 51.3 & 14 & 18 & $140 \cdot 1$ & 22.9 & 4 & 6 & $121 \cdot 7^{\mathrm{a}}$ & $19 \cdot 4$ & 4 & 6 & 85.9 & 17.5 \\
\hline Type 4 & 26 & 44 & $160 \cdot 9$ & $69 \cdot 0$ & 50 & 108 & 144.5 & 34.3 & 8 & 14 & $162 \cdot 2$ & $75 \cdot 2$ & 6 & 14 & 18 & 44.6 & 1 & 3 & $166 \cdot 7$ & - \\
\hline Type 5 & 0 & 0 & $N / A$ & & 2 & 4 & $129 \cdot 2$ & 5.9 & 0 & 0 & $\mathrm{~N} / \mathrm{t}$ & & 3 & 4 & $116 \cdot 7^{\mathrm{a}}$ & 14.4 & 6 & 13 & 108.9 & 9.4 \\
\hline Type 6 & 3 & 5 & $90 \cdot 0^{\mathrm{a}}$ & $13 \cdot 2$ & 7 & 14 & $98 \cdot 2^{\mathrm{a}, \mathrm{b}, \mathrm{c}}$ & 24.5 & 0 & 0 & $\mathrm{~N} / \mathrm{t}$ & & 3 & 4 & $80 \cdot 0^{a}$ & 34.6 & 17 & 25 & $96 \cdot 9$ & $53 \cdot 1$ \\
\hline Other & 2 & 2 & 152.5 & 3.5 & 3 & 6 & $185 \cdot 0^{b}$ & 61.4 & 0 & 0 & $\mathrm{~N} / \mathrm{t}$ & & 1 & 1 & $165 \cdot 0$ & - & 2 & 4 & 80.0 & $21 \cdot 2$ \\
\hline
\end{tabular}

$\mathrm{N} / \mathrm{A}$, not applicable.

*Glass types 1 to 6 (see Fig. 1) were presented for wine. Participants could indicate that they had used another glass type than those presented. $\dagger N$, number of participants.

$\ddagger n$, number of measurements. When a single participant performed more than one measurement for the portion size of a certain type of wine, the average of all measurements was used.

§A statistically significant mean difference was observed between the different glass types used for white wine $(P=0.001)$, for red wine $(P \leq 0.0001)$ and for other wine $(P=0.019)$. Glass types were significantly different from ${ }^{\mathrm{a}}$ glass type $4,{ }^{\mathrm{b}}$ glass type $3,{ }^{\mathrm{C}}$ other glass types $(P<0.05)$.

which represented the largest glass type for wine (see Fig. 1). Glasses used for red wine showed comparable results, with glass type 4 being significantly different from glass types $2(P \leq 0.0001)$ and $6(P=0.006)$, and glass type 3 (the second largest glass type for wine) differing significantly from glass types $2(P=0.005), 6(P=0.028)$ and other glass types $(P=0.037)$. For other wine, glass type 4 was significantly different from glass types $2(P=0 \cdot 034), 3$ $(P=0.027), 5(P=0.020)$ and $6(P=0.001)$. No significant difference in mean portion size was seen between the different glass types used for rosé $(P=0.455)$ and fortified wine $(P=0 \cdot 428)$.

For each type of glass in which straight spirits was poured, the mean portion size with SD are provided in Table 5. Glass type D was excluded from analysis, since it was used by just one participant who used it for a type of sherry and not for straight spirits. There was no significant mean difference in portion size between the glass types used for straight spirits $(P=0 \cdot 112)$.

\section{Discussion}

The present study quantitatively explored the portion sizes of wine, fortified wine and straight spirits poured at home in a sample of adults living in the Netherlands. Results revealed that the participants' portion sizes were on average larger than the Dutch standard drink sizes.

Participants poured about $30-40 \%$ more wine than the standard of $100 \mathrm{ml}$ and about $90 \%$ more fortified wine than the standard of $50 \mathrm{ml}$. The participants' portion sizes of wine remained on average smaller than the practicebased serving size of $150 \mathrm{ml}$ used by The Netherlands Nutrition Centre ${ }^{(4)}$, but the portion sizes of fortified wine 
Table 5 Portion sizes (in millilitres) of straight spirits compared by type of glass in 201 participants from Wageningen and surroundings, the Netherlands, August-September 2017

\begin{tabular}{lcccr}
\hline Type of glass* & $N \dagger$ & $n \ddagger$ & Mean§ & \multicolumn{1}{c}{ SD } \\
\hline Type A & 32 & 54 & $41 \cdot 7$ & $16 \cdot 3$ \\
Type B & 12 & 14 & $38 \cdot 4$ & $7 \cdot 9$ \\
Type C & 17 & 28 & $43 \cdot 2$ & $20 \cdot 2$ \\
Type E & 14 & 31 & 48.5 & $25 \cdot 6$ \\
Type F & 29 & 56 & $50 \cdot 0$ & $15 \cdot 6$ \\
Other & 10 & 11 & $55 \cdot 5$ & $17 \cdot 7$ \\
\hline
\end{tabular}

*Glass types A to F (see Fig. 1) were presented for straight spirits. Participants could indicate that they had used another glass type than those presented.

$\dagger N$, number of participants.

$\ddagger n$, number of measurements. When a single participant performed more than one measurement for the portion size of straight spirits, the average of all measurements was used.

$\S$ No statistically significant mean difference was observed between the glass types used for straight spirits $(P=0.112)$.

were on average larger than the practice-based serving size of $75 \mathrm{ml}$. The size and shape of glasses varied among wine types, with larger amounts of white wine and red wine poured into large glass types compared with smaller glass types. Participants poured on average 35\% more straight spirits than the standard of $35 \mathrm{ml}$, but not significantly less than the practice-based serving size of $50 \mathrm{ml}$ used by The Netherlands Nutrition Centre ${ }^{(4)}$. In addition, the higher the alcohol volume percentage was in straight spirits, the smaller was the portion size, but amounts still exceeded the standard of $35 \mathrm{ml}$. No significant differences between glass types used for straight spirits were detected. Similar results manifested when converting portion sizes (in millilitres) to alcohol content per serving (in grams), using reported volume percentages and an alcohol density of $0.789 \mathrm{~g} / \mathrm{ml}^{(20)}$. In fact, a portion of wine, fortified wine or straight spirit contained about $20-35 \%$ more alcohol than the standard amount of alcohol per serving ( $10 \mathrm{~g})$, except in the beverage types with the fewest measurements: the alcohol content per serving of other wine ( $n$ 18) did not deviate significantly from $10 \mathrm{~g}$, possibly due to lower statistical power.

These findings suggest that the use of the standard drink sizes in self-reporting methods might lead to an underestimation of alcohol consumption in the Netherlands. The current study supports the evidence of a previous study ${ }^{(21)}$ that considerable differences exist between people's perceptions of a standard drink and the actual definition of a standard drink, especially in relation to wine and spirits. This might affect the accuracy and precision of dietary surveys as well as recommendations on alcohol consumption in relation to health outcomes. The question arises whether using millilitres, or grams of alcohol, or other weight-based measures instead of the term 'glasses' in surveys could reduce measurement error, but these alternatives do not seem to be useful in helping drinkers to monitor alcohol intake ${ }^{(22-24)}$. Rather, it seems more effective to correct for under-reporting by using updated (i.e. larger) standard drink sizes, although the question remains whether systematic overpouring of alcoholic beverages is proportional to the total amount consumed. The present study cannot clarify this, because it was focused on pouring and not on consumption of alcoholic beverages. However, earlier validation studies ${ }^{(25)}$ and both laboratory and field studies ${ }^{(26)}$ reveal relatively high associations, showing that what is typically poured is typically drunk. Instead of correcting for under-reporting it might be worthwhile to educate consumers on the use of standard glasses; for example, by making use of unitmarked glasses, which seems to be effective in improving people's understanding and attitude towards unit-based guidelines to monitor their drinking ${ }^{(27)}$. This could result in both more precise data in dietary surveys and better follow-up of alcohol consumption recommendations.

Regarding participant characteristics, the present study showed differences in portion size between education levels for rosé only and differences in portion size between younger and older participants for other wine and strong spirits (>40\% vol.) only. These findings should, however, be interpreted with caution, because rosé, other wine and spirits of $>40 \%$ vol. were measured by relatively few participants. With respect to BMI, in a UK study investigating the association between sensitivity to food cues (sight and smell of food) and body weight, individuals' weight status was significantly associated with the tendency to desire larger portions of a cued food ${ }^{(28)}$. However, the present research did not demonstrate differences between average portion sizes of wine or straight spirits across BMI categories. Hence, BMI might not influence the desire for larger portions of alcoholic beverages per se. However, participants with high BMI values could have under-reported portion sizes in the present study. In a Dutch study investigating the associations between basic determinants and misreporting of dietary intake, BMI was the only consistent determinant of misreporting ${ }^{(29)}$.

Participants indicated in the survey which glass type was most similar to the glass that they used at home. Glass type seemed to be associated with portion size of wine, with larger amounts of white and red wine poured in larger glass types. However, the glasses that were provided as references differed in shape and size and could only be compared with each other visually. No details were given about the exact size of the glasses, because participants could have perceived this as a guide for pouring their beverages up to a certain amount.

Each participant was asked to do multiple measurements for the same type of alcoholic beverages, and although standard drink definitions were not provided, people could have become more aware of poured amounts after completing the first measurement. However, statistical analyses showed no significant difference between first and last measurements (data not shown).

The present study was conducted off-premises; participants measured portion sizes of wine and straight spirits at 
home rather than in a controlled environment. A limitation of this choice includes the inability to monitor the measurements and to check for compliance. However, monitoring is considered a time-consuming and costly process, and it may distract or influence participants in their actions. In addition, pouring at home is more likely to reflect a real-life situation, in which participants use their own beverages and glasses. Special attention was given to avoid social desirability bias. Since alcohol consumption is considered a sensitive topic where socially desirable responding is of concern ${ }^{(30)}$, participants were not asked about consumption patterns, but explicitly about poured amounts of alcoholic beverages. In addition, they received no information on standard drink sizes.

The present study included the use of identical measuring cups by the participants, maximizing internal validity. In addition, the present study is the first one in the Netherlands to address portion sizes of alcoholic beverages off-premises since Lemmens' study in $1994^{(15)}$. In line with the present results, Lemmens' study showed that self-reported drinks taken at home contained on average more than the presumed standard amount of alcohol (10g), with the highest deviation for spirits $(+26 \%)$, followed by fortified wines $(+14 \%)$ and wine $(+4 \%)^{(15)}$. Comparison of both studies should be interpreted with caution because they used different study designs and study subjects. For instance, Lemmens' study sample was drawn in 1985 from the general Dutch population and consisted of 863 participants, whereas the present study is limited by a smaller, more local and highly educated group of participants. Therefore, further research in a larger, nationally representative sample is recommended. Since alcoholic beverages are not only poured at home but also relatively often in restaurants ${ }^{(31)}$, complementary research could be carried out onpremises for a more comprehensive estimation of alcohol consumption in the Netherlands.

\section{Conclusion}

Portion sizes of wine, fortified wine and straight spirits poured at home in the Netherlands are on average larger than the Dutch standard drink sizes. This finding might indicate that at-home alcohol consumption of these beverages in the Netherlands is underestimated.

\section{Acknowledgements}

Financial support: This study was funded by the Dutch Beer Institute. Conflict of interest: M.L.J. and A.S. were employed by the Dutch Beer Institute during the study and during writing of the manuscript. They had no leading role in the design of the study, the analyses or in the decision to publish the results. M.F.A.d.B., J.H.M.d.V. and E.J.M.F. have no conflict of interest. Authorship: M.F.A.d.B. developed the research question and study design, analysed and interpreted the data, and drafted the manuscript. M.L.J. assisted in data cleaning and was, together with A.S. and J.H.M.d.V., involved in the data interpretation, manuscript preparation and supervision of the project. E.J.M.F. contributed to the manuscript preparation. All authors reviewed and approved the final manuscript. Ethics of human subject participation: For this study, no ethical approval was required as indicated by the Medical Ethics Committee of Wageningen University.

\section{References}

1. Health Council of the Netherlands (2015) Dutch Dietary Guidelines 2015. Publication no. 2015/24E. The Hague: Health Council of the Netherlands.

2. van Rossum CTM, Buurma EJM, Vennemann FBC et al. (2017) Food Consumption in 2012-2014 Compared to the Dutch Dietary Guidelines 2015. RIVM Briefrapport no. 2017-0095. Bilthoven: The Dutch National Institute for Public Health and the Environment.

3. Young LR \& Nestle MS (1995) Portion sizes in dietary assessment: issues and policy implications. Nutr Rev 53, $149-158$

4. The Netherlands Nutrition Centre (2016) Eettabel. The Hague: The Netherlands Nutrition Centre.

5. Carruthers SJ \& Binns CW (1992) The standard drink and alcohol consumption. Drug Alcohol Rev 11, 363-370.

6. White AM, Kraus CL, Flom JD et al. (2005) College students lack knowledge of standard drink volumes: implications for definitions of risky drinking based on survey data. Alcohol Clin Exp Res 29, 631-638.

7. Devos-Comby L \& Lange JE (2008) 'My drink is larger than yours?' A literature review of self-defined drink sizes and standard drinks. Curr Drug Abuse Rev 1, 162-176.

8. Banwell C (1999) How many standard drinks are there in a glass of wine? Drug Alcohol Rev 18, 99-101.

9. Gual A, Martos AR, Lligoña A et al. (1999) Does the concept of a standard drink apply to viticultural societies? Alcohol Alcohol 34, 153-160

10. Wansink B \& van Ittersum K (2005) Shape of glass and amount of alcohol poured: comparative study of effect of practice and concentration. BMJ 331, 1512-1514.

11. Kerr WC, Patterson D, Koenen MA et al. (2008) Alcohol content variation of bar and restaurant drinks in Northern California. Alcohol Clin Exp Res 32, 1623-1629.

12. Kerr WC, Greenfield TK, Tujague J et al. (2005) A drink is a drink? Variation in the amount of alcohol contained in beer, wine and spirits drinks in a US methodological sample. Alcohol Clin Exp Res 29, 2015-2021.

13. Gill JS \& Donaghy M (2004) Variation in the alcohol content of a 'drink' of wine and spirit poured by a sample of the Scottish population. Health Educ Res 19, 485-491.

14. Wilkinson C, Allsop S \& Chikritzhs T (2011) Alcohol pouring practices among 65- to 74-year-olds in Western Australia. Drug Alcohol Rev 30, 200-206.

15. Lemmens PH (1994) The alcohol content of self-report and 'standard' drinks. Addiction 89, 593-601.

16. Dawson DA (1998) Measuring alcohol consumption: limitations and prospects for improvement. Addiction $\mathbf{9 3}$, 965-968

17. Wansink B \& van Ittersum K (2003) Bottoms up! The influence of elongation on pouring and consumption volume. J Consum Res 30, 455-463.

18. EetMeetWeet (2011) EetMeetWeet. http://www.eetmeet weet.nl/leden/1242/5/0/40 (accessed June 2017). 
19. Limesurvey GmBH (2017) LimeSurvey: An Open Source survey tool. http://www.limesurvey.org (accessed June 2017).

20. Haynes WM (2011) CRC Handbook of Chemistry and Physics, 92nd ed. Boca Raton, FL: CRC Press.

21. Mongan D \& Long J (2015) Standard Drink Measures Throughout Europe; Peoples' Understanding of Standard Drinks and Their Use in Drinking Guidelines, Alcohol Surveys and Labelling. Dublin: Health Research Board.

22. Kerr WC \& Stockwell T (2012) Understanding standard drinks and drinking guidelines. Drug Alcobol Rev 31, 200-205.

23. Greenfield TK \& Kerr WC (2008) Alcohol measurement methodology in epidemiology: recent advances and opportunities. Addiction 103, 1082-1099.

24. Stockwell T, Blaze-Temple D \& Walker C (1991) The effect of 'standard drink' labelling on the ability of drinkers to pour a 'standard drink'. Aust J Public Health 15, 56-63.

25. Willett W \& Lenart E (2013) Reproducibility and validity of food-frequency questionnaires. In Nutritional Epidemiology, 3rd ed., pp. 96-141 [W Willett, editor]. New York: Oxford University Press.
26. Wansink B (1996) Can package size accelerate usage volume? J Mark 60, 1-16.

27. de Visser R, Brown C, Cooke R et al. (2017) Using alcohol unit-marked glasses enhances capacity to monitor intake: evidence from a mixed-method intervention trial. Alcohol Alcohol 52, 206-212.

28. Tetley A, Brunstrom J \& Griffiths P (2009) Individual differences in food-cue reactivity. The role of BMI and everyday portion-size selections. Appetite 52, 614-620.

29. Trijsburg L, Geelen A, Hollman PCH et al. (2017) BMI was found to be a consistent determinant related to misreporting of energy, protein and potassium intake using self-report and duplicate portion methods. Public Health Nutr 20, 598-607.

30. Davis CG, Thake J \& Vilhena N (2010) Social desirability biases in self-reported alcohol consumption and harms. Addict Behav 35, 302-311.

31. van Rossum CTM, Buurma-Rethans EJM, Vennemann FBC et al. (2016) The Diet of the Dutch: Results of the First Two Years of the Dutch National Food Consumption Survey 2012-2016. RIVM Letter report no. 2016-0082. Bilthoven: The Dutch National Institute for Public Health and the Environment. 